\title{
INTENÇÕES EMPREENDEDORAS DOS ESTUDANTES DE BAIXA RENDA: O CASO DO PROGRAMA CEARENSE DE INCUBAÇÃO CORREDORES DIGITAIS
}

Roberta Dutra De Andrade ${ }^{1}$

Gisele Aparecida Chaves Antenor ${ }^{2}$

Elda Fontinele Tahim ${ }^{2}$

${ }^{1}$ núcleo de inovação e empreendedorismo - INOVE / campus Quixadá / UNIVERSIDADE FEDERAL DO CEARÁ

${ }^{2}$ Universidade Estadual do Ceará 


\section{INTENÇÕES EMPREENDEDORAS DOS ESTUDANTES DE BAIXA RENDA: O CASO DO PROGRAMA CEARENSE DE INCUBAÇÃO CORREDORES DIGITAIS}

Resumo: É consenso que a criação de novas empresas é fator indispensável para a geração de estratégias de recuperação, crescimento econômico e competitividade. Esta pesquisa visa analisar o impacto da formação e incentivo ao empreendedorismo, na construção do perfil de jovens empreendedores. Assim, busca-se identificar influências que coalescem às intenções futuras de empreender por parte dos seus participantes, a partir do modelo de Carvalho e Gonzalez (2006), que abordou os fatores que influenciam a intenção empreendedora de jovens estudantes, como antecedentes pessoais, conhecimentos empresariais, motivações empreendedoras, autoeficácia empreendedora e contexto institucional. Analisamos o programa cearense Corredores Digitais, cujo o objetivo é a formação empreendedora de jovens de baixa renda; tendo abordagem qualitativa, exploratório-descritivo e procedimentos de pesquisa estudo de caso. Questionários semiestruturados com perguntas abertas, dicotômicas e de múltipla escolha, além de grupo focal com seis jovens finalistas do programa; foram os instrumentos utilizados para extração dos dados.

Palavras-chave: Empreendedorismo. Educação. Incentivo. Jovens.

\section{INTRODUÇÃ̃O}

As firmas são de fundamental importância para garantir o progresso social e econômico de seu entorno, gerando emprego e renda para a comunidade e competitividade para o país. Para Schumpeter (1942), as economias são incapazes de criar novos empregos em números suficientes para satisfazer a população economicamente ativa. Este fator, segundo Pereira (1991), aliado a supressões massivas de empregos e compressão de efetivos, faz com que os empresários, como agentes empreendedores, desempenham papel basilar para a solução do desemprego, já que considera o empreendedorismo, segundo a definição do Global Entrepreneurship Monitor, como qualquer tentativa de criar um novo negócio que pode envolver o auto emprego, uma nova organização ou a expansão de um negócio já existente atendendo às condições de risco e considerável grau de incerteza.

A criação de novas empresas, para Birley (1989), é fator substancial para a criação de estratégias de recuperação e crescimento econômico. Assim sendo, o empreendedorismo pode e deve ser ensinado e, principalmente, incentivado (DRUKER, 1985; OOSTERBEEK; PRAAG; IJSSELSTEIN, 2010; PARKER, 2007; KURTKO, 2005; ROXAS; CAYOCAPANIZALES, 2008; KUCKERTZ, 2011). A junção de empreendedorismo e educação é indispensável, uma vez que as instituições de ensino detêm recursos humanos de alta qualificação e um conjunto de conhecimento e habilidades indispensáveis para formação de pessoas capacitadas, desenvolvimento de novos ambientes e programas que estimulem o fomento de atividades de aprender fazendo (learning by doing) ligadas ao empreendedorismo (FAYOLLE; DEGEORGE, 2006; KURATKO, 2005; ROCHA; SILVA; SIMÕES, 2012).

Em uma sociedade de constante mudanças, a competitividade das empresas consiste em entregar novos produtos e negócios com maior valor agregado, Lucas (2001) observa que, embora a formação empreendedora tenha recebido investimentos crescentes, principalmente em um processo formal de aprendizagem do empreendedorismo em instituições de ensino, outros autores observam que muitos empreendimentos apresentam pouco desempenho inovador (IATA; ZIMMER, 2016). Dessa forma, Carvalho e Gonzales (2006) acreditam que as
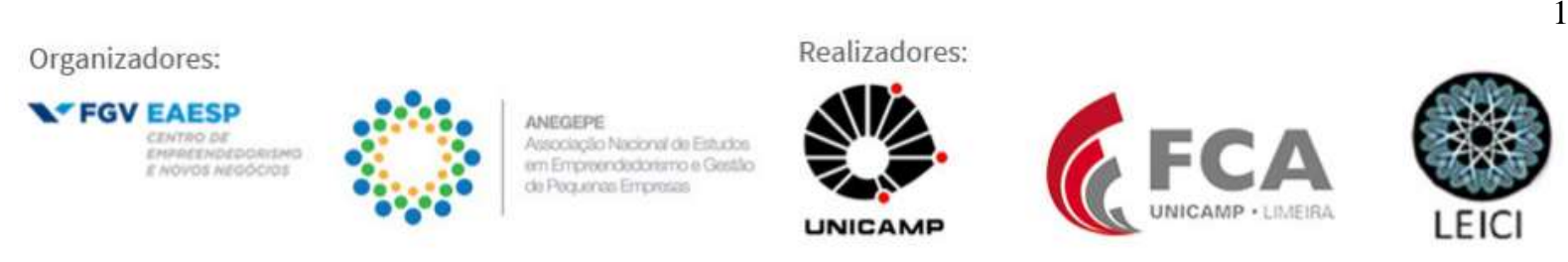
instituições de ensino devem apostar na formação orientada para a criação de empresas, onde alunos são enxergados como potenciais criadores e empreendedores.

A partir deste ponto de vista, parece capital investigar a figura do aluno como potencial empresário e empreendedor, que identifica oportunidade e cria novos negócios capazes de reunir recursos necessários para enfrentar riscos e incertezas e gerar emprego e renda. Tais alunos, potenciais empreendedores, devem reunir características individuais para o desempenho da função empresarial e competências para o entrepreneurship (SEARBOROUGH; ZIMMERER, 1993). Enxerga-se que diante do contexto global, tem aumentado o interesse pelo estudo das intenções empreendedoras em jovens, o crescimento do fomento a programas de formação e incentivo ao empreendedorismo e na construção do perfil empreendedor e sobre qual o impacto nas intenções futuras de empreender por parte dos seus participantes (AUDET, 2000; BRICE, 2002; CARVALHO; GONZALEZ, 2006; FRIZZO et al., 2016; KRUEGER; REILLY; CARSRUD, 2000; RAIJMAN, 2001; ROCHA; SILVA; SIMÕES, 2012).

Seguindo esta linha de análise e utilizando como ponto de partida o modelo teórico de Carvalho e Gonzalez (2006), que aborda diversos fatores que influenciam a intenção empreendedora de jovens estudantes, quais sejam: antecedentes pessoais, conhecimentos empresariais, motivações empreendedoras, auto eficácia empreendedora e contexto institucional; pretende-se analisar como tais fatores determinam a intenção empreendedora dos jovens em programas de formação em negócios. Para tanto, realizou-se um estudo de caso do programa Corredores Digitais, realizado em conjunto pela Secretaria da Ciência, Tecnologia e Educação Superior (SECITECE), Prefeituras municipais e Universidades e Escolas Profissionalizantes, cujo o objetivo foi a formação empreendedora de jovens de baixa renda do estado do Ceará.

O programa Corredores Digitais foi elaborado com metodologia pedagógica recomendada por investidores da área, direcionada para a criatividade e conceituação abstrata, permitindo a concepção de produtos inovadores, conciliando as vertentes teóricas e prática e criativa (PAÇO, et al., 2008; RAPOSO; et al., 2008). Este programa foi escolhido para análise por abranger oito municípios estrategicamente distribuídos ao longo do estado do Ceará: Fortaleza, Maracanaú, Quixadá, Beberibe, Jaguaribe, Sobral, Tauá e São Benedito. Localizado na região Nordeste do Brasil, o estado apresenta um longo contexto histórico de exclusão econômica, baixa renda, alto índice de miserabilidade e mortalidade infantil, atraso econômico e tecnológico amplificado pelo clima árido do sertão central e pela seca característica da região.

Nesse cenário, segundo o Serviço de apoio às micro e pequenas empresas do Ceará SEBRAE/CE, o número de negócios por conta própria cresce em função do número de pessoas que perderam seus empregos e não conseguiram se recolocar novamente no mercado de trabalho, o êxodo rural não qualificado e em função da falta de políticas públicas eficazes impulsionando o empreendedorismo local pela necessidade de auto geração de emprego e renda.

De natureza aplicada, este estudo foi realizado com abordagem qualitativa, com objetivo descritivo e procedimentos de pesquisa estudo de caso. Para esta pesquisa, utilizaram-se dois instrumentos de coleta de dados primários. Inicialmente foram aplicados questionários semiestruturados com perguntas abertas, dicotômicas e de múltipla escolha, baseados nos modelos de Spencer e Spencer (1993), Ajzen (1991), Shapero (1982), Davidson (1995) e, mais recentemente, em Carvalho e Gonzalez (2006). As entrevistas foram realizadas com vinte um
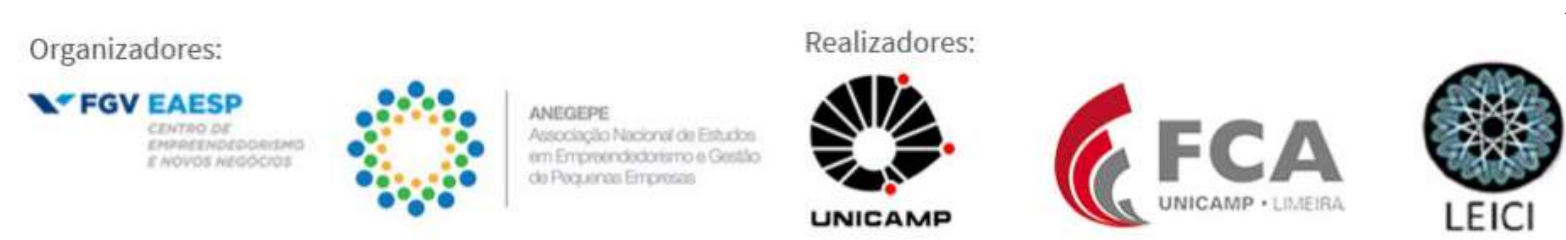
jovens que participaram da fase de incubação, de todos os municípios participantes. Em busca de aprofundamento no corpus empírico, foi realizado grupo focal com seis jovens finalistas do programa e, desta forma, foi possível realizar a triangulação das evidências empíricas obtidas.

\section{REFERENCIAL TEÓRICO}

\subsection{Empreendedorismo inovador}

Schumpeter (1942) define a inovação como um processo de descontinuidade no qual o desenvolvimento ocorre a partir de novas combinações por meio da produção de novos produtos ou melhoria de produtos já existentes pela utilização de métodos diferentes. Para Dolabela (1999), o empreendedorismo diz respeito a qualquer inovação que tenha alguma relação com a prosperidade da empresa de forma a fazer o empreendimento crescer na indústria em que está inserido.

Em face à inovação, Frizzo et al. (2016), preconiza que o empreendedor necessita de um método de gestão equivalente ao processo que deseja implementar, uma vez que a estrutura organizacional acarreta o dever de mudança de perfil dos gestores, que precisam resolver novos desafios gerados no processo de inovação, sob pena destes tornarem-se degenerativos para a firma (SOUZA, 2011).

Para Claiborne (2007), a busca por um novo perfil de empreendedor envolve aprendizagem coletiva em um contexto que permita alinhar condições sociais e resultados inovadores para garantir resultados e gerar aportes financeiros que sustentem o processo de inovação (LAZONIC, 2004). Parolin e Volpato (2008) entendem que as condições socioeconômicas influem diretamente no potencial empreendedor de alto valor agregado, potencial de crescimento e escalabilidade.

Face a diversas formas de fomentar a inovação, cabe destacar a parceria entre universidades e empresas e os programas de incubação e aceleração às iniciativas empreendedoras. A primeira é peça crucial na formação e no desenvolvimento de competências dos indivíduos contribuindo para o desenvolvimento de uma sociedade empreendedora. A segunda, impulsiona substancialmente o empreendedorismo inovador por meio da identificação, captação e aperfeiçoamento de ideias inovativas potenciais com propensão a transformar-se em negócios com alto valor agregado.

\subsection{Educação para o empreendedorismo}

Diversos autores definem a educação para o empreendedorismo como um processo que estimula indivíduos, de forma dinâmica e socializada, a identificar oportunidades para transformar suas ideias inovadoras em um conjunto de atividades práticas, lógicas e assinaladas, cujo objetivo principal é o desenvolvimento pessoal desse indivíduo e o conhecimento formal (ALBERTI, 2004; MATLAY, 2006; ODEGÄRD, 2011; POSTIGO; IACOBUCCI; TAMBORINI, 2006; RASHEED, 2000).

Nesse contexto, a educação representa um elemento crucial para o desenvolvimento de uma sociedade empreendedora, uma vez que é extremamente importante que haja uma formação específica para os jovens que estão próximos a entrar em uma vida profissional e economicamente ativa. A sensibilização desses jovens e a criação de programas de empreendedorismo podem estimulá-los a encarar o auto emprego como opção válida e por isso, a educação para o empreendedorismo já vem sendo prioridade na política de muitos países industrialmente desenvolvidos e em desenvolvimento (ALBERTO; SILVA, 2007; HUBER;
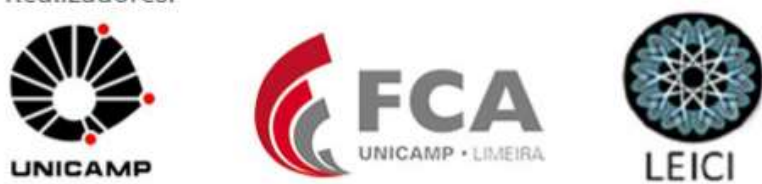
SLOOF; VAN PRAAG, 2012; KECKERTZ, 2011; LEPROUTE et al., 2010; PAÇO et al., 2011; ROXAS; CAYOCA-PANIZALES, 2008).

Apesar de flagrante parte da literatura entender que o empreendedorismo entre os jovens deve ser incentivado e fortalecido por tratar-se de peça-chave para o desenvolvimento econômico das nações, o estudo do impacto desses programas e atividades nos estudantes ainda não geram consenso visto que parte dos estudos conseguem demonstrar a relação entre as atividades de empreendedorismo com as intenções futuras de empreender destes jovens (CARVALHO; GONZALEZ, 2006; ROCHA, SILVA, SIMÕES, 2012; ODEGÄRD, 2011), e outra parte não revela conclusões sintomáticas (OOSTERBEEK; VAN PRAAG; IJSSELSTEIN, 2010).

\subsection{Intenções empreendedoras}

A análise das intenções empreendedoras serve para, ainda que de forma imperfeita, prever comportamentos nos indivíduos em relação à sua propensão em abrir seu próprio negócio (DAVIDSSON, 1995). De acordo com o objetivo deste trabalho, a pesquisa foi aplicada em um ambiente propício à existência de potenciais empreendedores e empresários: primeiro por tratar-se de jovens em um momento de vida que antecede a sua entrada em um mercado de trabalho e, segundo, por estes estarem vinculados à instituições de ensino superior ou profissionalizantes e, portanto, estão em processo de formação e podem ser influenciados pela existência de uma educação empreendedora.

Para Trice (1991) as aspirações profissionais de jovens em fase de formação permitem prever de forma relevante uma eventual escolha profissional futura. Para estudar as intenções empreendedoras no programa Corredores Digitais foi utilizado o modelo proposto por Carvalho e Gonzalez (2006), que além de trazer uma revisão de bibliografia (AJZEN, 1991; AUTIO et al., 1997; DAVIDSSON, 1995; SPENCER; SPENCER, 1993) sobre conhecimentos empresariais, características pessoais de empreendedores e intenções empreendedoras, adiciona aspectos ligados à criação da empresa e desempenho da função empresarial tendo em conta sua aplicação em estudantes do ensino superior. Tal modelo apresenta cinco instrumentos para avaliação dos elementos-chave das intenções empreendedoras em jovens graduandos tratados a seguir:

\subsubsection{Antecedentes pessoais}

Diversos autores consideram existir uma relação importante entre determinadas variáveis pertinentes aos antecedentes pessoais e o comportamento empreendedor além de traços de personalidade do próprio indivíduo e fatores de natureza sócio demográfica (LÓPEZ; POZO; MARTÍN, 1999; STANWORTH; BLYTHE, GRANGER, 1989). Especificamente nessa investigação interessam os elementos acadêmicos, demográficos e envolvente institucional e familiar.

A formação do empresário é tema que merece destaque embora apresente resultados controversos a depender do país onde foi analisado (DAVIDSSON, 1989; REYNOLDS, 1995; STOREY, 1994). Os estudos revelam que embora não seja estritamente necessário um alto nível de instrução para criar um negócio, as pessoas com nível educacional mais elevado podem ter maiores chances de êxito não só como empresários, como também trabalhando para outrem (HISRICH, 1990; VECIANA, 1989). Das hipóteses levantadas por Carvalho e Gonzalez (2006), espera-se que alunos nos últimos anos de graduação manifestem maior propensão à criação de empresas, assim como os alunos que trabalham e estudam.
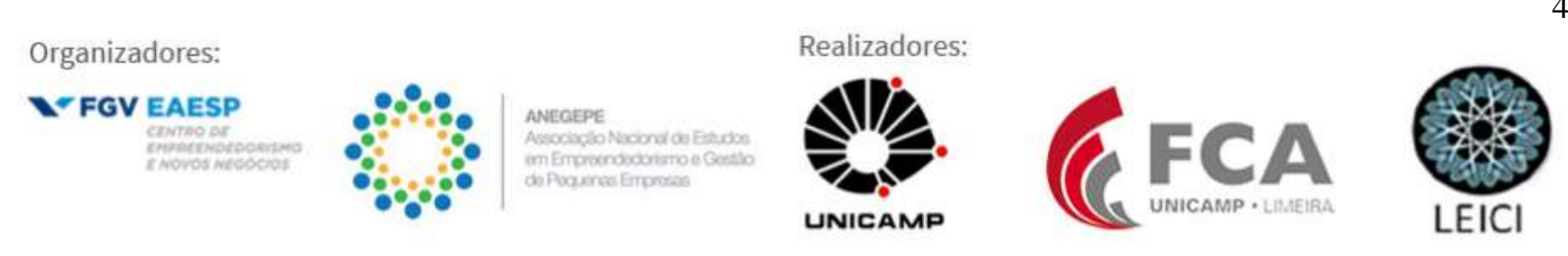
A idade também é considerada fator importante para a determinação das intenções empreendedoras e diversos autores alegam que os indivíduos costumam tomar a decisão de empreender entre 25 e 40 anos (BOCKHAUS, 1982; DAVIDSSON, 1995; PETROF, 1980; REYNOLDS, 1995). Em relação ao sexo, evidências empíricas apontam a existência de diferenças nos traços de personalidades entre os sexos e que os homens costumam ser mais empreendedores e a justificativa para tal estaria nas características psicológicas e na valorização do trabalho como realização pessoal (BRENNER, 1992; CARVALHO, 1997; SEXTON; BOWMAN-UPTON, 1990; WIT; VAN WINDEN, 1989).

Petrof (1980) e Carvalho (1997) sugerem que na maioria dos casos os empreendedores são os filhos mais velhos oriundos de famílias muito numerosas. Tal fato é reverberado por diversos outros autores que, ao afirmarem que existem muitas razões para explicar a relação entre discriminação social e propensão à criação de empresas por pessoas ou grupos sociais normalmente inseridos na marginalidade, servem de base para o empreendedorismo por necessidade, como forma de escapar dessa situação, tão comum no Brasil (DAVIDSSON, 1995; HAGEN, 1968; HOSELITZ, 1971; WILKEN, 1979). Uma infância difícil também é citado como fator característico de alguns empresários que os leva a criar sua empresa para fugir da pobreza e do abandono familiar (CARVALHO, 1997; COLLINS; MOORE, 1964; VECIANA, 1989).

Hagen (1968) e Gibb (1993) assinalam que a união da educação formal com a experiência profissional anterior gera mais conhecimentos e habilidades além de permitir a prática da função gerencial. Por último, os estudos de antecedentes familiares apontam para a relevância do fato de haver familiares empreendedores, nível de renda e formação acadêmica dos pais, além do fato de que grande parte dos empreendedores possuem parentes já empresários (COOLINS; MOORE, 1970; COOPER; DUNKELBERG, 1984; JACKOBOVITZ; VIDLER, 1982; SHAPERO; SOKOL, 1982).

\subsubsection{Conhecimentos empresariais}

Vasta literatura entende o conhecimento empresarial como o conjunto de competências necessárias ao desempenho da atividade empresarial (ADAM; CHELL, 1993; DURKAN et al., 1993; MAN, 2001; McCLEALLAND, 1987; SNELL; LAU, 1994; STUART; LINDSAY, 1996) e Carvalho e Gonzalez (2006) enfatiza a oportunidade, a estratégia, a organização, o relacionamento e o compromisso e o fator conceitual.

Para Man (2001), oportunidade é muito importante para o entrepreuneurship por ser a habilidade de identificar e tirar o maior proveito possível e de forma rápida e proativa das novas oportunidades de negócio que vão surgindo. Autores como Gasse at al. (1997), Mitton (1989) e McGregor et al., 2000) reconhecem a capacidade de relacionamento como fator de fundamental importância ao desenvolvimento do negócio, caracterizando-a como a capacidade de comunicação e persuasão nas relações interpessoais para obter benefícios de seus contatos e conhecimentos pessoais.

O conhecimento conceitual está associado ao conhecimento administrativo e diz respeito à capacidade cognitiva, à aprendizagem, e ao pensamento analítico orientado para a tomada de decisões e resoluções de problemas. É importante para manter a orientação e a eficácia do empreendedor por estar relacionada com a compreensão e visão amplificada do ambiente externo que permite a criação de perspectivas de longo prazo, definição de objetivos e, consequentemente, a formulação e implementação de estratégias (HUNT, 1998; LAU;
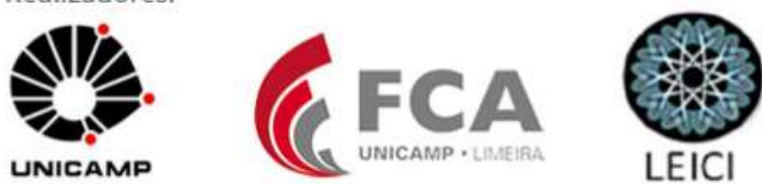
CHAN, MAN, 1999). Tais estratégias são definidas por Freire (1999) como o conjunto de decisões e ações que maior valor agregado aos clientes.

Aqui, Carvalho e Gonzalez (2006) afirma ser razoável supor que empreendedores de sucesso sejam pessoas normalmente diligentes, proativas, dedicadas e responsáveis e que quanto mais elevados seus conhecimentos empresariais, maior a probabilidade de empreender, uma vez que sente-se mais preparado para o desempenho da função empresarial.

\subsubsection{Motivações empreendedoras}

Os estudos investigativos dos motivos que levam pessoas a criarem seus próprios negócios abordam fundamentalmente alguns fatores motivacionais como: percepção da instrumentalidade da riqueza, necessidade de aprovação, independência e desenvolvimento pessoal (ALÄNGE; SCHEINBERG, 1988; CARVALHO, 1997; DUBINI, 1988; PEREIRA, 2001; SCHEINBERG; MACMILLAM, 1988). Para Veciana (1989), a necessidade de independência está conexa à realização pessoal, descrita como a perspectiva de criar sua própria empresa e colocar em prática suas ideias.

A necessidade de desenvolvimento pessoal está ligada a vontade de realizar bem as tarefas e atingir altos padrões de qualidade para alcançar realização pessoal, que, por sua vez, não faz alusão a obtenção de reconhecimento ou prestígio social. Normalmente, essa necessidade de realização está associada à aceitação de responsabilidades, propensão a assumir riscos e capacidades de inovar, planejar a longo prazo e avaliar o resultado de suas ações (BAMBERGER, 1986; HAMILTON, 1988; VECIANA, 1989, SHAPERO, 1982). A necessidade de aprovação apresenta variação de importância em diferentes países e culturas (CARVALHO, 1997; MCGRATH; MACMILLAN, 1992; WILKEN, 1979).

Por fim, Carvalho e Gonzalez (2006) sugerem que quanto maiores as motivações empreendedoras assinaladas pelas necessidades de autonomia, desenvolvimento pessoal, aprovação e percepção da instrumentalidade da riqueza, maiores serão suas intenções empreendedoras.

\subsubsection{Auto eficácia empreendedora}

Bandura elucidou a teoria da auto eficácia em 1977 para explicar a intensidade com que uma pessoa acredita em sua capacidade para realizar determinada tarefa ou ação. Afirmou tratar-se de um traço de personalidade que afeta a motivação, a seleção da carreira e a percepção individual de riscos e tolerância para assumi-los. Estudos posteriores apresentam a convicção individual como principal determinante para a intenção empreendedora avaliando a percepção do indivíduo sobre a viabilidade de abertura de um negócio (BOYD; VOZIKIS, 1994; DAVIDSSON, 1995; KRUEGER, 1994; SCHERER et al., 1989; ). Posto isso, o modelo adotado supõe que quanto maior a auto eficácia empreendedora, maior a disposição para criar uma empresa.

\subsubsection{Envolvente institucional}

Com base nos estudos de Autio et al. (1997) que avalia a influência da envolvente institucional a partir da percepção individual dos jovens, Carvalho e Gonzalez (2016) buscaram analisar se o ambiente das instituições podem favorecer e incentivar a iniciativa empreendedora dos alunos presumindo que a intenção de abrir seu próprio negócio cresce junto com a percepção da influência do ambiente institucional em sua formação.

Neste estudo será investigado se programas para formação empreendedora têm realmente algum impacto direto nos jovens estudantes de graduação e ensino profissionalizante
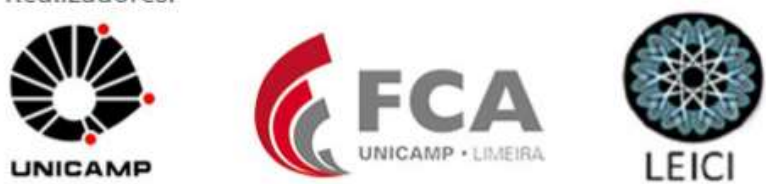
ou se as perspectivas deles antes de participarem do programa se mantém inalteradas no que diz respeito ao interesse em abrir um negócio e ter um perfil empreendedor ou ter um emprego estável sem intenções de abrir sua própria empresa.

O programa analisado, Corredores Digitais, foi escolhido por possuir vertentes teóricas e práticas que estimulam a criatividade e permitem a concepção de novos produtos e serviços inovadores. As atividades propostas passaram por discussões com professores, articuladores locais, desenvolvedores de conteúdo, mentores de negócio e mentores de desenvolvimento em tecnologia da informação para validar as diferentes abordagens de empreendedorismo junto aos jovens.

Dentre essas abordagens, destacam-se os treinamentos à distância em diversos temas análogos ao empreendedorismo, acompanhamento presencial, mentorias de negócio e de programação e desenvolvimento de produtos tecnológicos, workshops para criação de ideias inovadoras e marketing digital, bootcamp para apresentação das ideias ao público, concurso de ideias desenvolvidas com cronograma de entregas programadas e, por fim, um demoday para os jovens empreendedores apresentarem seus planos de negócios para uma banca de investidores.

\section{METODOLOGIA}

Estudos recentes sobre intenções empreendedoras encontrados na literatura são de abordagem quantitativa, em que buscam avaliar a relação entre a intenção empreendedora à fatores e variáveis que possam a determinar. A pergunta, em geral, é o quanto a determinam. Neste estudo buscou-se verificar o como determinam e para tanto, a abordagem qualitativa se mostrou a mais apropriada. De acordo com Stake (2011), na pesquisa qualitativa o pesquisador buscam dados que representam a experiência das pessoas em situações específicas. A natureza da pesquisa é aplicada, uma vez que visa gerar conhecimentos para aplicação prática dirigidos à solução de problemas específicos, conforme define Prodanova e Freitas (2013). Quanto aos objetivos, trata-se de uma pesquisa descritiva, onde, de acordo com Prodanova e Freitas (2013), os fatos são observados, registrados, analisados, classificados e interpretados, sem que o pesquisador interfira sobre eles. Neste sentido, a pesquisa em questão buscou descrever as características de um grupo de alunos que participaram de um programa de empreendedorismo, tentando verificar como os fatores e variáveis determinaram a intenção destes em empreenderem.

Esta pesquisa se apoiou nos procedimentos do estudo de caso, uma vez que envolveu o estudo profundo de um objeto de pesquisa, de maneira que permitiu o seu amplo e detalhado conhecimento, como preconiza Yin, 2001. De acordo com o mesmo autor, esse procedimento pode permitir novas descobertas de aspectos que não foram ainda revelados ou previstos inicialmente. Para Martins (2006) a estratégia de pesquisa com estudo de caso pode orientar a busca de explicações e interpretações convincentes para situações que envolvam fenômenos sociais complexos, assim como a concepção de uma teoria explicativa do caso que possibilite condições para se fazerem inferências analíticas sobre proposições constatadas no estudo e outros conhecimentos encontrado.

Nesta pesquisa o objetivo de análise foi o programa cearense coordenado pela Secretaria da Ciência, Tecnologia e Educação Superior (SECITECE), denominado Corredores Digitais, cujo o objetivo é a formação empreendedora de jovens de baixa renda, oriundos de instituições de ensino superior e escolas profissionalizantes do estado. O programa se dividiu nas fases de
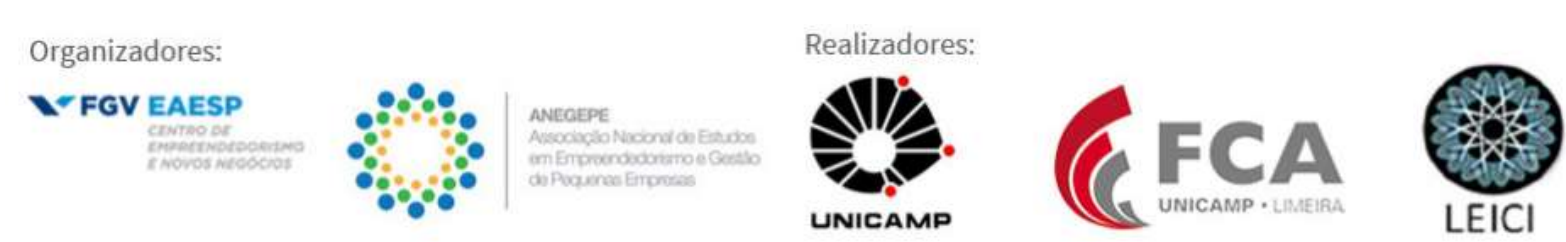
pré- incubação, incubação e demoday. A pré-incubação iniciou-se pela divulgação e lançamento do desafio que buscou propostas de soluções baseadas nos Objetivos de Desenvolvimento Sustentável da ONU (Organização das Nações Unidas). As inscrições foram online e poderiam se inscrever grupos formados por até 3 pessoas, preferencialmente das áreas de Tecnologia da Informação, Administração e Design. Cada equipe precisaria apresentar uma proposta de negócio, um mínimo produto viável de baixa fidelidade e uma apresentação que atendesse a pelo menos um objetivo da ONU.

A partir de uma primeira seletiva, onde uma banca avaliadora analisou os modelos de negócio preenchidos em formato Canvas e as apresentações do tipo pitch enviadas pelos grupos, foram selecionadas 10 equipes por município, formadas por três pessoas cada, com exceção de Fortaleza, que por ser capital contou com dois polos totalizando 20 equipes. Os municípios foram: Fortaleza, Maracanaú, Tauá, Jaguaribe, Sobral, Beberibe, Quixadá e São Benedito. Para prosseguirem rumo a fase de "capacitação empreendedora". As equipes vencedoras passaram por formação em empreendedorismo, por meio de Ensino à Distância (EAD), utilizando-se de plataforma online com os seguintes conteúdos: comportamento empreendedor; como fazer um pitch matador; gamification; big data; internet das coisas; moviment maker; economia colaborativa e criando um negócio de sucesso.

Após a formação em empreendedorismo, foi realizada mais uma seletiva, desta vez para a fase de "incubação", onde continuaram no programa quatro equipes de cada município. Os incubados então receberam apoio de mentores em business e em desenvolvimento e ajuda de custo para a confecção de um MVP (Minimum Viable Product). Esta fase durou quatro meses e a cada quinze dias as equipes faziam entregas parciais do modelo de negócio e do MVP. Foram trinta e seis equipes incubadas e destas, doze foram até a fase final de Demoday, que constitui-se de apresentações pitch para banca de avaliadora composta por investidores. Além da premiação por classificação, os grupos tiveram acesso a possíveis investidores e, em alguns casos, prosseguimento de negociações.

Para esta pesquisa foram utilizados dois instrumentos de coleta de dados primários. Inicialmente utilizou-se de questionários semiestruturados com perguntas abertas, dicotômicas e de múltipla escolha, baseados nos modelos de Spencer e Spencer (1993), Ajzen (1991), Shapero (1982), Davidson (1995); Man (2001) e, mais recentemente, em Carvalho e Gonzalez (2006), que traz como fatores determinantes para a intenção empreendedora os antecedentes pessoais, conhecimentos empresariais, motivações empreendedoras, percepção de auto eficácia empreendedora e envolvimento institucional. As entrevistas foram realizadas com vinte um jovens que participaram da fase de incubação, de todos os municípios participantes. Em busca de aprofundamento no corpus empírico, foi realizado grupo focal com seis jovens finalistas do programa. As entrevistas e a reunião de grupo focal foram gravados e transcritos. A análise se deu por conteúdo, que de acordo com Bardin (2011) caracteriza-se por tentar compreender as formas de comunicações para além dos seus significados imediatos, que enriquece a tentativa exploratória e análise sistemática de todas as formas de expressão, formais e informais. A análise de conteúdo é, portanto, conjunto de técnicas de análise das comunicações, que utiliza procedimentos sistemáticos e objetivos de descrição do conteúdo das mensagens (BARDIN, 2011).

\subsection{Amostra e coleta de dados}

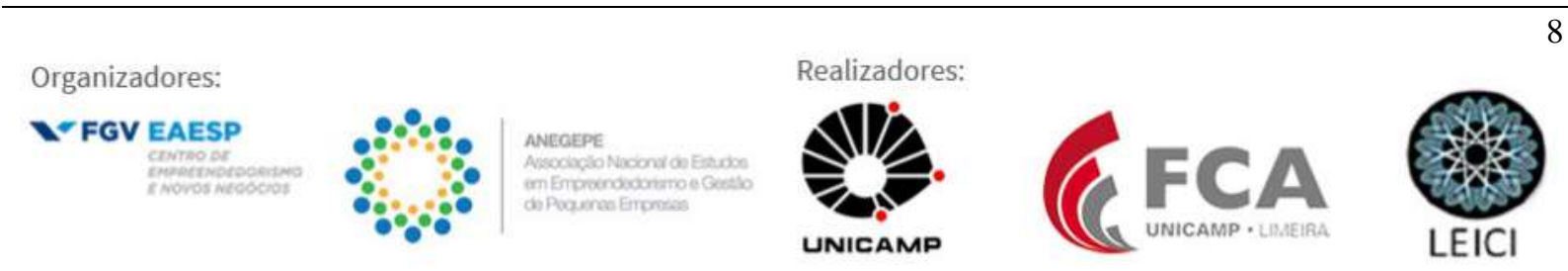


A população em estudo foram jovens, regularmente matriculados no ensino superior ou profissionalizante, que participaram e concluíram o programa Corredores digitais. Estes foram escolhidos como população por estudarem em cursos relacionados à área de tecnologia da informação e afins, áreas ditas fundamentalmente inovadoras, e por estarem situados ao longo de um dos estados mais atrasados tecnológica e economicamente do país resultando, em muitos casos, em empreendedorismo por necessidade de auto geração de emprego e renda (SEBRAE/CE, 2016).

Foram entrevistados 21 jovens participantes e finalistas do programa de um total de 32 finalistas. Ademais, realizou-se uma conversa com um grupo focal formado por seis participantes, totalizando 27 jovens ouvidos. Com idade média entre 18 e 21 anos, a maior parte dos jovens acessados foram do município de Quixadá (15), seguidos pelos de Fortaleza (4), Sobral e Beberibe (3) cada um, Tauá (1) e Maracanaú (1). De todos os municípios participantes do programa, São Benedito foi o único sem participantes entrevistados.

Nesta investigação, recorreu-se ao modelo proposto por Carvalho e Gonzalez (2006) para identificar os fatores determinantes da intenção empreendedora considerando que a concretização de uma ideia ou negócio é precedida pela intenção e que esta é entendida como um estado de espírito em que a atenção do indivíduo está apontado para determinada situação com vista ao alcance de metas (BIRD, 1988).

\section{ANÁLISE E DISCUSSÃO DOS RESULTADOS}

\subsection{Antecedentes pessoais}

Em geral, todos os jovens relataram experiências profissionais anteriores, seja como estagiários, desenvolvedores de software, designer e até mesmo vendedores. Apenas 4 jovens não tinham experiência profissional. Sobre a formação dos pais, doze jovens tinham pais que estudaram até o ensino médio; dez o fundamental; e um a alfabetização. Apenas três chegaram ao nível superior, um chegou a fazer pós-graduação. Nove jovens tinham experiências de empreendedorismo na família.

Com relação a renda familiar, mais de $50 \%$ dos jovens tinham renda familiar de até um salário mínimo. 33\% até três salários mínimos e 17\% de três a seis salários mínimos. Verificouse que $77 \%$ dos jovens dependiam economicamente dos pais.

\subsection{Conhecimentos empresariais}

A abordagem utilizada para identificar a percepção dos entrevistados sobre os elementos chave da intenção empreendedora foi usar perguntas-estímulo para evocação da narrativa dos respondentes. Então, nas entrevistas e no grupo focal os pesquisadores convidaram os respondentes a se colocarem no lugar de um empresário e fazer uma autoavaliação quanto aos seus conhecimentos... "Se eu fosse proprietário de uma empresa, considero ter habilidades e conhecimentos para..." e foi solicitado que escolhessem e comentassem os conhecimentos que se sentem habilitados a praticar.

Dentre os principais conhecimentos empresariais, a saber, oportunidade, relacionamento, conceptual, organização, estratégia e compromisso, os que os entrevistados mais se declaram habilitados a fazer em um negócio foram os relacionados a oportunidade, como criar novos produtos e serviços. Essa é, de acordo com Man (2001), uma das características mais distintivas do empreendedor. Para o autor o que define o empresário e seu sucesso é o sentido de oportunidade, observação e ação de acordo com as oportunidades. $77 \%$ dos entrevistados se declararam preparados para identificar oportunidades.
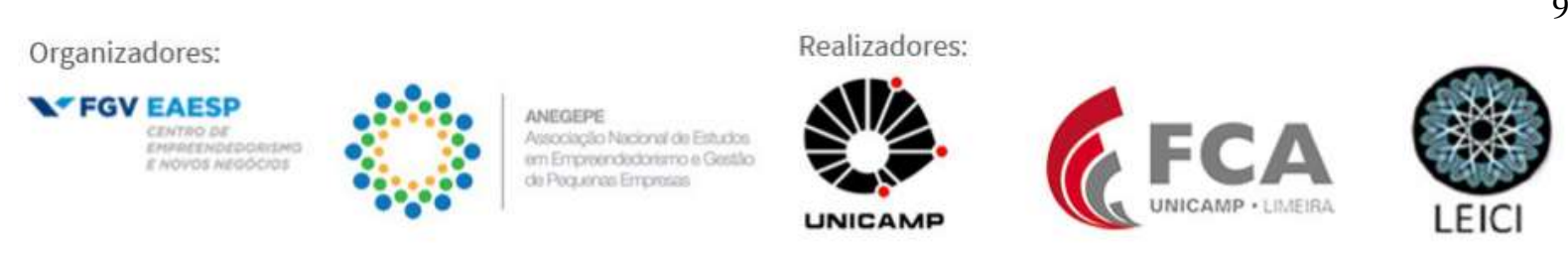
As habilidades com relação a relacionamento ainda são um desafio para os estudantes. Comunicar-se de forma correta, foi o conhecimento que apenas 7 dos respondentes se sentem habilitados, apesar de acharem que se relacionam e interagem parcialmente bem com as pessoas. "Estamos mediano. Estamos crescendo nesse quesito. Precisamos melhorar a timidez, o nervosismo, a forma de prender a atenção das pessoas, de chegar nas pessoas...", declarou R. R. Carvalho e Gonzalez (2006) defendem como importante a habilidade de o empreendedor tirar proveito do seus contatos e conhecimentos pessoais e para tanto precisa desenvolver sua capacidade de comunicação, persuasão e relações interpessoais.

Do ponto de vista conceitual, que representa a capacidade cognitiva, analítica, aprendizagem, tomada de decisão e resolução de problemas (CARVALHO e GONZALEZ, 2006), verificou-se que apesar de apenas 8 jovens se sentirem preparados para aplicar suas próprias ideias na empresa, o dobro deles, ou seja, 16, se sentem aptos a implantar ideias inovadoras na empresa. Para tal questão, os jovens se declararam ainda pouco propensos a correr riscos: "prefiro aplicar soluções que já tiveram sucesso em outros lugares", como afirma A.P.

Enfrentar os problemas sob diferentes pontos de vista e até mesmo como oportunidade foram apontados pelos jovens como uma forma de descobrir novas ideias e oportunidades para a empresa, como afirma R.M. "Nós tentamos ver o problema por vários ângulos, sentamos, conversamos e tentamos ver o melhor pra empresa e dentro dessas várias ideias que surgiu de cada um vamos gerando a solução. Às vezes a gente lista e vê qual é a melhor". Como critério para analisar as ideias os jovens afirmam: "o que vai ser melhor pra empresa. Menos risco e vai ser melhor pra gente". É possível verificar que apesar de aprofundarem-se no problema e analisá-lo por várias perspectivas, a tomada de decisão é baseada na solução com menor risco possível. É possível identificar a concordância das falas com Carvalho e Gonzalez (2006) quando afirmam que o empreendedor deve ter "capacidade de ter visão alargada das questões, ter uma perspectiva de longo prazo e tomar decisões complexas", porém percebemos ainda visão conservadora quanto a propensão a riscos, características intrínseca a empreendedores inovadores.

Quanto aos conhecimentos relacionados a organização da empresa, os respondentes ficaram nitidamente divididos. Enquanto 15 se sentiram aptos a coordenar tarefas e liderar, apenas oito se sentiram capazes de planejar as operações do negócio, supervisionar subordinados e gerir os recursos da empresa. Chandler e Jansen (1992) nos trazem a necessidade da função administrativa para o bom desempenho da empresa. Um dos entrevistados que participou do grupo focal revelou: "neste momento acho que tá mais centralizado em uma pessoa, às vezes duas do nosso projeto... A gente fez a divisão de quem ficaria responsável e pelo que. Mas sempre, sempre, sempre eram pauta de reunião dos projetos dos planejamentos que a gente faria..., que precisávamos de um líder. Não existe hierarquia no grupo".

Outra capacidade que se pressupõe função principal do empreendedor é a direção da empresa, por meio do desenvolvimento e implementação de estratégias para alcançar os objetivos do negócio (FREIRE, 1999; CARVALHO e GONZALEZ, 2006). Nesta temática verificou-se a segunda maior habilidade considerada pelo respondentes, a de analisar os resultados da empresa. Entretanto, as habilidades que antecedem e que dão conta da elaboração do plano estratégico da empresa, organização do trabalho em função dos objetivos da empresa,
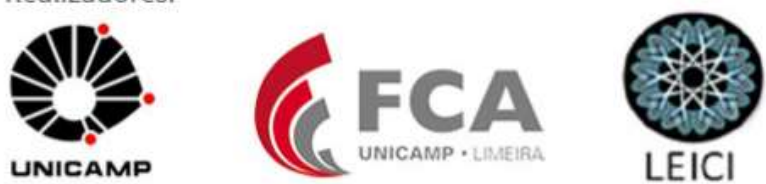
estruturar o negócio e avaliar os negócios tendo em conta os objetivos definidos foram consideradas por dez respondentes como "parcialmente" habilitados. Apenas dez se considerou apto a executar essas funções. Os demais se declararam ainda não aptos.

O compromisso e a atitude responsável e proativa dos empresários, além do rigor determinação também são habilidades decisivas para um empreendedor gerir sua empresa (MAN, 2001; CARVALHO e GONZALEZ, 2006). Metade dos entrevistados desta pesquisa se sentiam preparados com relação a estes conhecimentos empresariais.

De acordo com a pesquisa de Carvalho e Gonzalez, (2006, pág. 52), "que quanto mais elevados forem os conhecimentos empresariais, maior será a probabilidade do indivíduo ter uma intenção favorável à alternativa de criar seu próprio negócio", uma vez que se sentirão mais preparados, percebe-se ainda nas respostas obtidas que tais conhecimentos ainda não estão plenamente consolidados, apesar da capacitação e experiência que tiveram por meio do programa.

\subsection{Motivações empreendedoras}

Tentando compreender os motivos que levam os indivíduos a criarem sua própria empresa a partir de estudos teóricos e empíricos encontrados no trabalho de Man (2001) e aprimorado nos estudos de Carvalho e Gonzalez, 2006), que necessidades de independência, desenvolvimento pessoal, percepção da instrumentalidade da riqueza e de aprovação social são os principais fatores motivacionais.

Quando perguntado aos entrevistados "Eu gostaria de criar minha própria empresa para..." e apresentado em uma ficha as opções relacionadas aos fatores motivacionais acima, obtivemos as seguintes respostas. Quanto à independência, 73\% dos entrevistados avaliaram que o principal motivo para criarem uma empresa seria a possibilidade de pôr em prática suas próprias ideias. Tal resultado chama a atenção visto que essa foi uma habilidade pouco dominada no campo dos conhecimentos empresariais, como analisada no item anterior. A necessidade de independência superou as necessidades de autonomia no trabalho e maior flexibilidade. Para I.C, é uma forma de também mitigar riscos: "se tiver trabalhando para alguém, você tem aquele risco, mas você trabalhando no seu negócio, se quebrar, no outro dia já pode começar de novo".

Sobre a necessidade de desenvolvimento pessoal constatamos que estão de acordo com McClelland (1987), precursor na investigação destes fatores, visto que os entrevistados revelam que empreenderiam para implementar negócio inovador e para sua própria realização pessoal, como declara I.C "eu penso que quando a pessoa contrata a gente é pra construir os sonhos delas, eu quero trabalhar para construir os meus sonhos". Tais fatores superaram inclusive a escolha de empreender para serem ricos ou a possibilidade de aumentar os rendimentos. Para Veciana (1989) o desejo de independência, alcançar padrões de excelência e prestígio social são mais prementes do que a generalização de que a obtenção de riqueza.

De acordo com a pesquisa de Carvalho e Gonzalez, (2006, pág. 55), “quanto mais elevadas forem as motivações empreendedoras designadas por necessidade de independência ou autonomia, necessidade de desenvolvimento pessoal, percepção da instrumentalidade de riqueza e necessidade de aprovação", maior será sua intenção favorável à criar sua própria empresa. Percebe-se claramente que os jovens pesquisados têm intenções empreendedoras em aspectos como independência, desenvolvimento pessoal e de aprovação social. Não foi tão perceptível quanto ao fator obtenção de riqueza, talvez explicado pelos

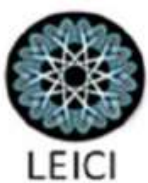


antecedentes pessoais com relação a idade, dependência dos pais, não sendo responsáveis economicamente pelas suas famílias. Estudos mais aprofundados sobre esse fator podem ser indicados.

\subsection{Auto eficácia empreendedora}

Considerando a auto eficácia explicada pelo grau que cada pessoa acredita nas suas próprias capacidades para desempenhar suas funções, produzir resultados e obter sucesso, dez dos entrevistados se avaliaram auto eficazes para serem empresários de sucesso e dezoito avaliaram-se eficazes para obtenção da independência sendo empresários. Todos avaliaram baixas as possibilidades de falência eventual, caso abrissem seu próprio negócio. Mas para Rodrigo, a possibilidade de falência baixa está mais relacionada à área em que atua, conforme sua fala: "Eu acho que seria poucas, porque na nossa área a quantidade de novas tecnologias pra surgir é inúmeras, então acho que seria pouco por isso. Tem pouca possibilidade de falir, porque tem muita tecnologia pra surgir e serem aproveitadas".

Para Carvalho e Gonzalez, (2006, pág. 56), "quanto mais elevada for a percepção de auto eficácia empreendedora, maior será a probabilidade de intenção favorável ao empreendedorismo". Constata-se que na pesquisa em questão os jovens se sentem auto eficazes na maior parte dos fatores, apesar de em alguns casos se avaliarem que a área em que atuam seja mais determinante do que sua capacidade.

\subsection{Envolvimento institucional}

Tentando avaliar se o ambiente institucional no qual estão envolvidos, qual seja, suas universidades e o próprio programa Corredores Digitais, verificou-se que apesar de ainda não se sentirem tão bem preparados para seguirem a carreira de empresários e não encontrarem muitos alunos empreendendo, encontram nos ambientes citados motivação para o empreendedorismo, autonomia para realização de trabalhos e sobretudo, são encorajados a pôr em prática suas próprias ideias. No grupo focal, obtivemos os seguintes relatos: "R.D - Pra mim foi favorável, porque na própria minha Universidade tinha equipes concorrendo e a própria Universidade deu o suporte pra gente com a questão de sala, de mentores, orientadores e isso foi de suma importância pro nosso crescimento. P.O - O programa me deu uma base pra mim iniciar qualquer tipo de empreendimento, então futuramente se eu quiser colocar qualquer tipo de negócio eu vou ter uma bagagem que os Corredores Digitais me ofereceu.

\section{CONSIDERAÇÕES FINAIS}

Esta pesquisa teve como ponto de partida o modelo teórico de Carvalho e Gonzalez (2006), que abordou os fatores que influenciam a intenção empreendedora de jovens estudantes como antecedentes pessoais, conhecimentos empresariais, motivações empreendedoras, auto eficácia empreendedora e contexto institucional. Pretendeu-se analisar como tais fatores determinaram a intenção empreendedora dos jovens participantes do Programa Corredores Digitais, realizado em conjunto pela Secretaria da Ciência, Tecnologia e Educação Superior (SECITECE), Prefeituras municipais e Universidades e Escolas Profissionalizantes, cujo o objetivo foi a formação empreendedora de jovens de baixa renda do estado do Ceará.

O estudo foi realizado com abordagem qualitativa, de natureza aplicada, com objetivo descritivo e procedimentos de pesquisa estudo de caso. Dois instrumentos de coleta de dados primários foram utilizados: questionários semiestruturados com perguntas abertas, dicotômicas e de múltipla escolha, baseados nos modelos de Carvalho e Gonzalez (2006). As entrevistas

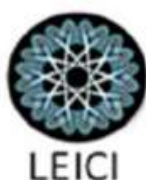


foram realizadas com vinte um jovens e foi realizado grupo focal com seis jovens finalistas do programa.

A abordagem utilizada para identificar a percepção dos entrevistados sobre os elementos chave da intenção empreendedora foi usar perguntas-estímulo para evocação da narrativa dos respondentes. Então, nas entrevistas e no grupo focal os pesquisadores convidaram os respondentes a se colocarem no lugar de um empresário e fazer uma autoavaliação "e se...".

Ao final da análise e discussão dos resultados foi possível constatar a importância do programa para a formação dos jovens, apesar de verificar que em poucos fatores verificou-se total propriedade por parte dos jovens. Para Carvalho e Gonzalez (2006) quanto mais os indivíduos se apropriam dos fatores que consideram determinantes para intenção empreendedora, mais estarão propensos a empreender. Constatou-se que a experiência proporcionada pelo Programa Corredores Digitais foi fundamental para formar e oferecer a prática do "empreender", entretanto, os conhecimentos empresariais ainda não estão completamente consolidados. Estudos sobre a metodologia de ensino-aprendizagem podem ser indicados para verificar tal questão e quem sabe a proposição de práticas pedagógicas adequadas.

Verificou-se que os jovens pesquisados têm intenções empreendedoras em aspectos como independência, desenvolvimento pessoal e de aprovação social, mais até do que ao fator obtenção de riqueza, talvez explicado pelos antecedentes pessoais com relação a idade, dependência dos pais, não sendo responsáveis economicamente pelas suas famílias. Estudos mais aprofundados sobre esse fator podem ser indicados.

A propensão a riscos ainda foi um fator limitante quanto à intenção empreendedora dos jovens que participaram da pesquisa. Mas como os próprios respondentes indicaram, os ambientes institucionais que fazem parte do seu cotidiano estão cada vez mais os instigando ao empreendedorismo, inovação e, sobretudo, a desenvolverem e colocarem suas ideias em prática. Os modelos tradicionais de trabalho estão passando por profundas mudanças e as aspirações do jovens também. O reconhecimento social e a possibilidade de contribuírem com a sociedade com inovações se tornam cada vez mais importantes do que a generalização da obtenção do lucro por si só. Não restam dúvidas que programas e outros mecanismos de formação e mais que isso, de práticas empreendedoras precisam ser estimulados e aprimorados.

\section{REFERÊNCIAS}

Adam, E., \& Chell, E. (1993). The successful international entrepreneur: A profile. In 23rd European Small Business Seminar. Belfast.

Ajzen, I. (2011). Theory of planned behavior. Handb Theor Soc Psychol Vol One, 1(2011), 438.

Alberti, F. (2004), «Entrepreneurship education: notes on an ongoing debate». 14th Annual IntEnt Conference, Nápoles, julho. Extraído de http://www.scielo.mec.pt/scielo.php?script=sci_nlinks\&ref=000133\&pid=S0873$7444201200040000500001 \& \operatorname{lng}=$ pt.

Alberto, D. e Silva, M. (2007), «Ensino do empreendedorismo: análise comparativa da situação em universidades Estado-Unidenses, Europeias e Chinesas». IX Seminário Luso-Espanhol de Economia Empresarial, Covilhã, novembro.

Alänge, S., \& Scheinberg, S. (1988). Swedish entrepreneurship in a cross-cultural perspective (pp. 1-15).

Allen, I. E., Elam, A., Langowitz, N., \& Dean, M. (2007). Global entrepreneurship monitor. 2006 report on women and entrepreneurship.

Audet, J. (2000, January). Evaluation of two approaches to entrepreneurship education using an intention-based model of venture creation. In Allied Academies International Conference. Academy of Entrepreneurship. Proceedings (Vol. 6, No. 1, p. 1). Jordan Whitney Enterprises, Inc.
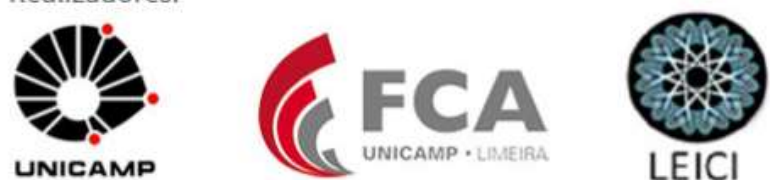
Autio, E., Keeley, R. H., Klofsten, M., \& Ulfstedt, T. (1997). Entrepreneurial intent among students: testing an intent model in Asia, Scandinavia and USA.

Bamberger, I. (1986). The Stratos Project: theoretical bases and some first descriptive results. In 4th Nordic Research Conference on Small Business, Umeå/Vasa, June (pp. 4-6).

Bandura, A. (1977). Self-efficacy: toward a unifying theory of behavioral change. Psychological review, 84(2), 191.

Bardin, L. (2011). Análise de Conteúdo/Laurence Bardin; Tradução Luís Antero Reto, Augusto Pinheiro. São Paulo: Edições, 70 .

Bird, B. (1988). Implementing entrepreneurial ideas: The case for intention. Academy of management Review, 13(3), 442-453.

Birley, S. (1989). Female entrepreneurs: are they really any different?. Journal of small business management, 27(1), 32.

Boyd, N. G., \& Vozikis, G. S. (1994). The influence of self-efficacy on the development of entrepreneurial intentions and actions. Entrepreneurship theory and practice, 18, 63-63.

Brenner, O. C. (1982). Relationship of education to sex, managerial status, and the managerial stereotype. Journal of Applied Psychology, 67(3), 380.

Brice, J. (2004). The role of personality dimensions on the formation of entrepreneurial intentions. In Annual Usasbe National Conference (Vol. 18).

Carvalho, P. M. R. D. (1997). Características e motivações dos empresários: O caso dos fundadores de pequenos negócios na cidade da Guarda (Doctoral dissertation, Universidade da Beira Interior).

Carvalho, P., \& González, L. (2006). Modelo explicativo sobre a intenção empreendedora. Comportamento Organizacional e Gestão, 43-65.

Chandler, G. N., \& Jansen, E. (1992). The founder's self-assessed competence and venture performance. Journal of Business venturing, 7(3), 223-236.

Collins, O. F., \& Moore, D. G. (1964). The enterprising man (Vol. 1). Michigan State Univ Pr.

Cooper, A. C., \& Dunkelberg, W. C. (1984). Entrepreneurship and paths to business ownership. Institute for Research in the Behavioral, Economic, and Management Sciences, Krannert Graduate School of Management, Purdue University.

Davidsson, P. (1995). Determinants of entrepreneurial intentions.

De Wit, G., \& Van Winden, F. A. (1989). An empirical analysis of self-employment in the Netherlands. Small Business Economics, 1(4), 263-272.

Dolabela, F. (1999). Oficina do empreendedor.

Drucker, P. F. (1985). Innovation and entrepreneurship practices and principles. AMACON.

Dubini, P. (1989). The influence of motivations and environment on business start-ups: Some hints for public policies. Journal of business venturing, 4(1), 11-26.

Durkan, P., Harrison, R., Lindsay, P., \& Thompson, E. (1993). Competence and executive education and development in an SME environment. Irish Business and Administrative Research, 14(1), 65-80.

Fayolle, A., \& Degeorge, J. M. (2006). Attitudes, intentions, and behaviour: New approaches to evaluating entrepreneurship education. International entrepreneurship education. Issues and newness, 74-89.

Freire, A. (1997). Estratégia: sucesso em Portugal.

Frizzo, K., Da Silva, S. J. P., Carolina, M., Ferreira, Z., \& Gomes, C. M. (2016). Desempenho do programa de pré-incubação como catalizador do empreendedorismo inovador. $26^{a}$ conferência Anprotec. Extraído de http://www.anprotec.org.br/moc/anais/Artigo_Completo_Kamila\%20Frizzo.pdf

Gasse, Y., dAmboise, G., Simard, G., \& Lasker, K. (1997). Entrepreneurial-Managerial Competencies and Practices of Growing SMEs-Summary of Results from an Empirical Study (Preliminary). Quebec: Centre for Entrepreneurship and SME and Entrpreneiurat Laval, Universite Laval

Gibb, A. A. (1993). Enterprise culture and education understanding enterprise education and its links with small business, entrepreneurship and wider educational goals. International small business journal, 11(3), 11-34.

Hagen, E. E. (1971). La teoría económica del desarrollo. Amorrortu Editores.

Hamilton, R. T. (1987). Motivations and aspirations of business founders. International Small Business Journal, 6(1), 70-78.

Hisrich, R. D. (1990). Entrepreneurship/intrapreneurship. American Psychologist, 45(2), 209.

Hoselitz, B. F. (1971). Industrialización y sociedad. Madrid: Fundación Foessa. 
Huber, L. Sloof, R. \& Van Praag, M. (2012). The effect of early entrepreneurship education: evidence from a ransomized field experiment. The institute for the study of labour, Discussion Parrer $\mathrm{n}^{\circ}$ 6512, 4-22.

Hunt, J. M. (1997). Toward the development of a competency model of family firm leadership.

Jacobowitz, A., \& Vidler, D. C. (1982). Characteristics of entrepreneurs: Implications for vocational guidance. The Career Development Quarterly, 30(3), 252-257.

Krueger, N. (1994). Strategic Optimism: Antecedents of Perceived Probabilities of New Venture Success. In Academy of Management meeting, BPS Division.

Krueger, N. F., Reilly, M. D., \& Carsrud, A. L. (2000). Competing models of entrepreneurial intentions. Journal of business venturing, 15(5), 411-432.

Kuckertz, A. (2011). Entrepreneurship education-status quo and prospective developments.

Kuratko, D. F. (2005). The emergence of entrepreneurship education: Development, trends, and challenges. Entrepreneurship theory and practice, 29(5), 577-598.

Lau, T., Chan, K. F., \& Man, T. W. Y. (1999). Entrepreneurial and managerial competencies: small business owner-managers in Hong Kong. Hong Kong Management and Labour: Change and Continuity, Routledge, London, 220-236.

Lazonick, W. (2004). Indigenous innovation and economic development: Lessons from China's leap into the information age. Industry and Innovation, 11(4), 273-297.

Leproute, J.; Van Den Berghe, W.; Tilleuil, O. e Crinjs, H. (2010), «A new approach to testing the effects of entrepreneurship education among secondary school pupils».

Lucas, E. (2001). A disseminação da cultura empreendedora e a mudança na relação universidade-empresa. Encontro de estudos sobre empreendedorismo e gestão de pequenas empresas, II, Londrina. 241-252.

Man, W. Y. T. (2001). Entrepreneurial competencies and the performance of small and medium enterprises in the Hong Kong services sector (Doctoral dissertation, The Hong Kong Polytechnic University). http://www.vlerick.com/en/12958-VLK/version/default/part/AttachmentData/data/vlgms-wp-201001.pdf.

Matlay, H. (2006), «Researching entrepreneurship and education - Part 2: What is entrepreneurship education and does it matter?». Education + Training, 48(8/9), pp. 704-718.

McClealland, D. C. (1987), «Characteristics of successful entrepreneurs». Journal of Creative Behavior, vol.(3), pp. 219-233.

McGrath, R. G., \& MacMillan, I. C. (1992). More like each other than anyone else? A cross-cultural study of entrepreneurial perceptions. Journal of Business Venturing, 7(5), 419-429.

McGregor, J., \& Tweed, D. (2001). Gender and managerial competence: support for theories of androgyny?. Women in Management Review, 16(6), 279-287.

Mitton, D. G. (1989). The complete entrepreneur. Entrepreneurship Theory and Practice, 13(3), 9-19.

Odegärd, I. Entrepreneurship education in Norway. Extraído de http://www.regjeringen.no/upload/KDVedlegg/Grunnskole/Entrepreneurship\%20in\%20Education\%20in\%20Norway.pdf.

Oosterbeek, H., Van Praag, M., \& Ijsselstein, A. (2010). The impact of entrepreneurship education on entrepreneurship skills and motivation. European economic review, 54(3), 442-454.

de Oslo, O. M. (2005). Diretrizes para coleta e interpretação de dados sobre inovação. Organização para a Cooperação e Desenvolvimento Econômico.

Paço, A.; Ferreira, J.; Raposo, M.; Rodrigues, R. e Dinis, A. (2011), «Behaviors and entrepreneurial intention: empirical findings about secondary students». Journal of International Entrepreneurship, vol.(9), pp. 20-38.

Parolin, H., \& Volpato, M. (2008). Faces do Empreendedorismo Inovador. Curitiba: SENAI/SESI/IEL.

Pereira, F. J. C. (2001). A representação social do empresário: factores de criação de empresas.

Pereira, J. C. D. S. (1991). Criar uma empresa: Alternativa ao desemprego. Colecção Estudos $n^{o}$.

Petrof, J. V. (1980). Entrepreneurial profile: A discriminant analysis. Journal of Small Business Management (pre1986), 18(000004), 13.

Postigo, S., Iacobucci, D., \& Tamborini, M. F. (2006). Undergraduate students as a source of potential entrepreneurs: a comparative study between Italy and Argentina. International entrepreneurship education, issues and newness. Edward Elgar Publishing Limited, Cheltenham, 218-240.

Prodanov, C. C., \& de Freitas, E. C. (2013). Metodologia do Trabalho Científico: Métodos e Técnicas da Pesquisa e do Trabalho Acadêmico. $2^{\mathrm{a}}$ Edição. Editora Feevale. 
Raijman, R. (2001). Determinants of entrepreneurial intentions: Mexican immigrants in Chicago. The Journal of Socio-Economics, 30(5), 393-411.

Raposo, M. L. B., Ferreira, J. J. M., do Paço, A. M. F., \& Rodrigues, R. J. G. (2008). Propensity to firm creation: empirical research using structural equations. International Entrepreneurship and Management Journal, 4(4), 485-504.

Rasheed, H. (2000). Developing Entrepreneurial Potential in Youth of Entrepreneurial Education and Venture Creation. International Journal of Entrepreneurship Education, 5(3), 83-109.

Reynolds, P. D. (1995). Who starts new firms? Linear additive versus interaction based models. Frontiers of entrepreneurship research, 32-46.

Rocha, A., Silva, M. J., \& Simões, J. (2012). Intenções empreendedoras dos estudantes do ensino secundário: o caso do programa de empreendedorismo na escola. Economia Global e Gestão, 17(ESPECIAL), 77-97.

Roxas, B. G., Cayoca-Panizales, R., \& de Jesus, R. M. (2008). Entrepreneurial knowledge and its effects on entrepreneurial intentions: development of a conceptual framework. Asia-Pacific Social Science Review, 8(2), 6177.

Rubio López, E. A., Cordón Pozo, E., \& Agote Martín, Á. L. (1999). Actitudes hacia la creación de empresas: un modelo explicativo. Revista Europea de Dirección y Economía de la Empresa, 8(3), 37-52.

Scarborough, N. M., \& Zimmerer, T. (1996). Effective small business management (Vol. 2). Prentice Hall.

Scheinberg, S., \& MacMillan, I. C. (1988). An 11 country study of motivations to start a business. Babson College. Scherer, R. F., Adams, J. S., Carley, S., \& Wiebe, F. A. (1989). Role model performance effects on development of entrepreneurial career preference.

Schumpeter, J. A. (1942). Socialism, capitalism and democracy. Harper and Brothers.

Sexton, D. L., \& Bowman-Upton, N. (1990). Female and male entrepreneurs: Psychological characteristics and their role in gender-related discrimination. Journal of business venturing, 5(1), 29-36.

Shapero, A., \& Sokol, L. (1982). The social dimensions of entrepreneurship.

Snell, R., \& Lau, A. (1994). Exploring local competences salient for expanding small businesses. Journal of Management Development, 13(4), 4-15.

Spencer, L. M. (2003). y SPENCER, SM (1993): Competence at work. Modeles for.

Stake, R. E. (2011). Pesquisa qualitativa: estudando como as coisas funcionam. Penso Editora.

Stanworth, J., Stanworth, C., Granger, B., \& Blyth, S. (1989). Who becomes an entrepreneur?. International Small Business Journal, 8(1), 11-22.

Storey, D. J. (2016). Understanding the small business sector. Routledge.

Trice, A. D. (1991). A retrospective study of career development: I. Relationship among first aspirations, parental occupations, and current occupations. Psychological Reports, 68(1), 287-290.

Veciana, J. M. V. (1989). Características del empresario en España. Papeles de economía española, (39), 19-36 Wilken, P. H. (1979). Entrepreneurship: A comparative and historical study. Norwood, NJ: Ablex Publishing Corporation.

Yin, R. K. (2001). Estudo de Caso: Planejamento e Métodos. Bookman editora.

Zimmer, P., Mitsuê Iata, C., Artur de Souza, J., de Almeida Cunha, C., \& José, C. (2016). Tax Incentives for Innovation in Brazil: Obstacles for Use of the Good Law (Law 11.196/2005). Journal of technology management \& innovation, 11(4), 38-46. 